\title{
A Proposed Etiology of Psychogenic Nonepileptic
}

\section{Seizures}

\author{
Catherine A. Carlson ${ }^{1}$ \\ ${ }^{1}$ Minnesota Judicial Branch Fourth Judicial District, Psychological \\ Services Division, Minneapolis, Minnesota, United States
}

Int J Epilepsy 2018;5:e1

Concerning the article "A Proposed Etiology of Psychogenic Nonepileptic Seizures" by Catherine A. Carlson, there is an ongoing conflict of interest dispute raised by key clinicians and practitioners from different societies.
Address for correspondence Catherine A. Carlson, PsyD, LP, Psychological Services Division, 300 South 6th Street C-509, Minneapolis, MN, United States (e-mail: carlsonc32@gmail.com).

For these reasons, the Editorial Board gives the notice that the article is retracted by the Editor-in-Chief in accordance with COPE guidelines. 